\title{
Dietary fiber, mineral elements profile and macronutrients composition in different edible parts of Opuntia microdasys (Lehm.) \\ Pfeiff and Opuntia macrorhiza (Engelm.)
}

Hassiba Chahdoura, ${ }^{\mathrm{a}, \mathrm{b}}$, Patricia Morales ${ }^{\mathrm{c}}$, João C.M. Barreira, ${ }^{\mathrm{a},}$, Lillian Barros ${ }^{\mathrm{a}}$, Virginia Fernández-Ruiz $^{c}$, Isabel C.F.R. Ferreira ${ }^{\mathrm{a}, *}$, Lotfi Achour $^{\mathrm{b}}$

${ }^{a}$ Mountain Research Centre (CIMO), ESA, Polytechnic Institute of Bragança, Campus de Santa Apolónia, Ap. 1172, 5301-855 Bragança, Portugal.

${ }^{b}$ Laboratoire de Recherche "Bioressources": Biologie Intégrative \& Valorisation", Institut Supérieur de Biotechnologie de Monastir, Avenue Tahar Hadded, BP 74, 5000, Université de Monastir, Monastir, Tunisia.

${ }^{c}$ Dpto. Nutrición y Bromatología II, Facultad de Farmacia, Universidad Complutense de Madrid (UCM), Pza Ramón y Cajal, s/n. E-28040 Madrid, Spain.

*Authors to whom correspondence should be addressed (e-mail: iferreira@ipb.pt, telephone +351273303219, fax +351273325405; e-mail: jbarreira@ipb.pt, telephone +351273303309 , fax +351273325405$)$. 


\begin{abstract}
Nowadays, we are living in the era of functional foods. People are constantly seeking for new healthier food products, mainly derived from plants, with bioactive components such as fiber and/or mineral elements, in suitable and healthy ratios. Cactus (Opuntia spp.), which includes more than 1500 species, presents high potential to be considered as a functional food, as it was revealed by the phytochemical profiles and antioxidant activity previously demonstrated in different botanical parts of Opuntia microdasys (Lehm.) Pfeiff and Opuntia macrorhiza (Engelm.). In this follow-up work, morphological characters, nutritional composition, and particularly fiber and mineral elements profiles of these two species were characterized in the cladodes, pulp and seeds. Most of these parameters were also studied in their juice. Both species presented similar chemical profiles, but each of the different studied botanical parts presented great differences, as revealed by principal component analysis. Accordingly, the obtained results reinforce Opuntia spp. as a potential functional food, indicating also the botanical parts with highest adequacy to act as source of a specific constituent.
\end{abstract}

Keywords: Opuntia spp.; dietary fiber; mineral elements; atomic absorption spectroscopy; PCA. 


\section{Introduction}

Nowadays, consumers are highly concerned in following a healthy diet with low caloric value, low levels of cholesterol and saturated fats. In addition, consumer preference is often related with the ingestion of the so called functional foods, due to their potential positive effects on health. Among the top priorities, consumers seek food products with high dietary fiber content, since a daily intake of $25 \mathrm{~g}$ of fiber is recommended in order to prevent different pathologies, namely constipation, colon cancer, cardiovascular disease and obesity, among others (Ternent et al., 2007; Ayadi et al., 2009; Jae Hwan et al., 2012). Dietary fiber refers to food material, particularly plant material, that is not hydrolyzed by endogenous enzymes secreted by the human digestive tract, but that may be digested by gut microflora (IFST, 2007). The mineral content of any food commodity is also of high importance, since mineral elements (at suitable levels) play a vital role in human health: acid-base balance maintenance; osmotic regulation of fluid and oxygen transport in the body; action in catalytic processes within enzymatic activities associated with metabolic, endocrine and immune systems; essential in bones growth and formation (McDowell, 2003; Nabrzyski, 2007; Soetan et al., 2010).

Cactus (Opuntia spp.) is considered to have originated in tropical America, but it has been introduced to other regions of the world, such as Europe (particularly the Mediterranean countries) and Africa. More than 1500 species of cactus (Cactaceae family) belong to the Opuntia genus and many of them produce edible and highly flavored berry type fruits. These fruits consist of a thick pericarp (skin) with a number of clefts of small prickles, reddish purple, yellow or white in colour, with a luscious sweet pulp intermixed with a number of small seeds (Felker et al., 2005; Abdel-Hameed et al., 2014). The cladodes (vegetable stems) are used in many varieties of salad, after being cut in small cubes and immerged in vinegar; fruits are used for the extraction of 
juice and as jam ingredients, as well as to produce a special type of honey named "the Honey of Tuna". Opuntia fruits are also used for the extraction of natural pigments and to prepare an alcoholic beverage named "Colonche" (Touil et al., 2000). Although this cactus spp. has been used for many years as common functional foods, with medicinal and cosmetic purposes, they have not been a focus of research. Only in recent years, the scientific community has been focused to increase knowledge regarding the nutritional and health-promoting benefits of Opuntia spp. Furthermore, prickly pear fruit is one of the most representative fruits in some cultures and has recently gained attention for its nutritional value. Its high levels of betalains, taurine, dietary fiber, some minerals (calcium and magnesium) and antioxidants deserve special attention (Piga, 2004; PrietoGarcía et al., 2006; Morales et al., 2012). In terms of their bioactivity, Opuntia spp. cladodes and fruits are mostly known for their medicinal benefits, including arteriosclerosis, diabetes, gastritis, and hyperglycemia treatment (Lee et al., 2002). A thorough review of literature indicated the lack of studies reporting dietary fibers and minerals composition in Opuntia spp Tunisian varieties. Therefore, different botanical parts (cladodes and different fruit parts, as skin, pulp and seeds) and the juice of Opuntia mycrodasis (Lehm.) Pfeiff and Opuntia macrorhiza (Engelm.) were characterized for their nutritional composition, highlighting in dietary fiber and mineral elements composition. With the obtained results, it was expected to evaluate the possibility of using Opuntia spp. as sources of functional ingredients in food industry, or to consider these plants as functional foods per se.

\section{Material and methods}




\subsection{Samples}

Opuntia mycrodasis (Lehm.) Pfeiff (Figure 1A) and Opuntia macrorhiza (Engelm.)

(Figure 1B) were collected from the Cliff of Monastir (Tunisia) between June and July 2013. The cladodes and the fruits were washed and manually peeled, after removing of uncolored sides. The cladodes were cut in small portions. The skin of fruits was removed and the pulp (edible portion) was separated from the seeds and subtracted of any mucilaginous material. The juice was extracted by mechanical pressure avoiding contact with any metallic surface. All botanical parts (cladodes, skin, pulp and seeds) and the obtained juice were lyophilized and stored in the dark at $-20{ }^{\circ} \mathrm{C}$ until analysis.

\subsection{Morphological properties}

The number of selected terminal fruiting cladodes and fruits was defined according to well established practices (Valdez-Cepeda et al., 2013). All cladodes were selected from the uppermost part of the plants ensuring they were 1-year-old. All cladodes were cleaned with distilled water, paper-dried to remove washing water and immediately weighted. Length and width of each fruit and cladode were measured using a caliper micrometer.

\subsection{Chemical composition}

Moisture, protein, fat and ash were determined following the AOAC procedures (Latimer, 2012). The crude protein content $(\mathrm{N} \times 6.25)$ was estimated by the macroKjeldahl method; the crude fat was determined using a Soxhlet apparatus by extracting a known weight of sample with petroleum ether; the ash and mineral content was determined by incineration at $550 \pm 15^{\circ} \mathrm{C}$. Total carbohydrates were calculated by difference. Energy was calculated according to the following equation (Regulation (EC) 
No. 1169/ 2011 of the European Parliament and of the Council, of 25 October 2011): Energy $(\mathrm{kcal} / 100 \mathrm{~g} \mathrm{fw})=4 \times(\mathrm{g}$ protein $+\mathrm{g}$ carbohydrate $)+2 \times(\mathrm{g}$ fiber $)+9 \times(\mathrm{g}$ fat $)$

\subsection{Soluble and insoluble dietary fiber assay}

AOAC enzymatic-gravimetric methods (993.19 and 991.42) were used for soluble dietary fiber (SDF) and insoluble dietary fiber (IDF) analysis (Latimer, 2012). In brief, freeze-dried samples were treated with alpha-amylase (heat-stable), protease and amyloglucosidase.

The soluble and insoluble fractions were separated by vacuum filtration. Waste from the digests was dried at $100{ }^{\circ} \mathrm{C}$, and protein content was determined in the residue. Total fiber is the sum of soluble and insoluble fiber fractions; both were expressed as $\mathrm{g} / 100 \mathrm{~g}$ fw sample.

\subsection{Mineral elements (Macro and microelements)}

Total mineral content (ashes) and mineral elements analysis were performed on dried samples. The method 930.05 of AOAC was used (Latimer, 2012); $500 \mathrm{mg}$ of each sample were subject to dry-ash mineralization at $550^{\circ} \mathrm{C} \pm 15{ }^{\circ} \mathrm{C}$. The residue of incineration was extracted with $\mathrm{HCl}(50 \% \mathrm{v} / \mathrm{v})$ and $\mathrm{HNO}_{3}(50 \% \mathrm{v} / \mathrm{v})$ and made up to an appropriate volume with distilled water, where $\mathrm{Fe}, \mathrm{Cu}, \mathrm{Mn}$ and $\mathrm{Zn}$ were directly measured. An additional 1/10 (v/v) dilution of the sample extracts and standards was performed to avoid interferences between different elements in the atomic absorption spectroscopy: for $\mathrm{Ca}$ and $\mathrm{Mg}$ analysis in $1.16 \% \mathrm{La}_{2} \mathrm{O}_{3} / \mathrm{HCl}$ (leading to $\mathrm{LaCl}_{2}$ ); for $\mathrm{Na}$ and $\mathrm{K}$ analysis in $0.2 \% \mathrm{CsCl}$ (Fernández-Ruiz et al., 2011; Ruiz-Rodríguez et al., 2011). All measurements were performed in atomic absorption spectroscopy (AAS) with air/acetylene flame in Analyst 200 Perkin Elmer equipment (Perkin Elmer, Waltham, 
MA, USA), comparing absorbance responses with $>99.9 \%$ purity analytical standard solutions for AAS made with $\mathrm{Fe}\left(\mathrm{NO}_{3}\right)_{3}, \mathrm{Cu}\left(\mathrm{NO}_{3}\right)_{2}, \mathrm{Mn}\left(\mathrm{NO}_{3}\right)_{2}, \mathrm{Zn}\left(\mathrm{NO}_{3}\right)_{2}, \mathrm{NaCl}, \mathrm{KCl}$, $\mathrm{CaCO}_{3}$ and $\mathrm{Mg}$ band. The results were expressed in $\mathrm{mg}$ per $100 \mathrm{~g}$ of fresh weight.

\subsection{Statistical analysis}

For each botanical part, three independent samples were used for each species. Each of the samples was taken from pooled cladodes, fruits, seeds, juices or pulps. Data were expressed as mean \pm standard deviation. All statistical tests were performed at a $5 \%$ significance level using SPSS software, version 22.0 (IBM Corp., USA).

For each botanical part and parameter, a $t$-student test was applied to check for statistically significant differences among cultivars. The homogeneity of variance was tested by means of the Levene's test.

Principal components analysis (PCA) was applied as pattern recognition unsupervised classification method. The number of dimensions to keep for data analysis was assessed by the respective eigenvalues (which should be greater than one), by the Cronbach's alpha parameter (that must be positive) and also by the total percentage of variance (that should be as higher as possible) explained by the number of components selected. The number of plotted dimensions was chosen in order to allow meaningful interpretations.

\section{Results and discussion}

\subsection{Morphological characteristics}

O. microdasys and $O$. macrorhiza are very distinct plants, despite belonging to the same genus. O. microdasys is shorter (approximately $60-80 \mathrm{~cm}$ tall) and the cladodes present

dense areoles (Figure 1), without true spines, presenting also glochids in the center of these "pseudo-spines". In the studied samples, the cladodes dimensions varied around 
$12 \mathrm{~cm}$ long vs. $9 \mathrm{~cm}$ wide, weighting about $61 \mathrm{~g}$ (Table 1). O. macrorhiza, on the other hand, is a much higher plant, reaching about 2-5 $\mathrm{m}$ high, and the cladodes (Figure 1) present long spines ( 3 to $8 \mathrm{~cm}$ ) besides being considerably bigger: around $23 \mathrm{~cm}$ long vs. $14 \mathrm{~cm}$ wide and weighting about $163 \mathrm{~g}$ (Table 1). The fruits of both Opuntia also showed noticeable differences (Table 1), especially concerning the weight (5-fold higher for $O$. macrorhiza) and also regarding its density (data not tabled), since the fruits of $O$. macrorhiza had an approximate volume only 2-fold higher than those of $O$. mycrodasis. Besides these features, the fruit of $O$. mycrodasis present a deep red-purple colored pulp and thick peel with very small glochids (20 to 50/fruit), while the fruits of $O$. macrorhiza are red, and have few glochids (about $8 /$ fruit). The seeds of $O$. macrorhiza are as well higher, being also more lignified than O. mycrodasis' seeds. All the morphological characters are comparable with those reported in the same species (Bergaoui et al., 2007), presenting lower dimensions than those found in Opuntia ficusindica (Valdez-Cepeda et al., 2013). In view, of the potential use of Opuntia as a food or feed product, these morphological differences act favoring O. macrorhiza (the dimensions were statistically higher in all cases), since the biomass yields achievable using this species are significantly higher.

\subsection{Nutritional composition}

Despite the significant differences in the morphological characters, the nutritional composition from different parts of $O$. mycrodasis and $O$. macrorhiza presented some resemblance, especially concerning to their pulp (Table 2). The cladodes, pulp and juice presented similar composition with moisture as the major component, followed by carbohydrates and ash content. Carbohydrates were the major component in the seeds of both fruits $(61 \mathrm{~g} / 100 \mathrm{~g}$ fw in both species). The highest levels of protein were also found 
in the seeds (2.3 and $2.9 \mathrm{~g} / 100 \mathrm{~g}$ fw for O. mycrodasis and O. macrorhiza, respectively), with a significant difference $(p=0.014)$ among the two species. Fat contents showed significant differences in all botanical parts (except for juice, in which fat was not found), with higher contents in $O$. mycrodasis, concerning the cladode and the pulp, and in the seeds of $O$. macrorhiza. The fat contents in this part might be considered as having some potential for oil extraction, especially considering the type of fatty acids usually present in Opuntia seeds, which might represent a major contribution to the dietary intake of essential fatty acids (especially oleic and linoleic acids) in populations who traditionally include these fruits in the diet (Sawaya and Khan, 1982). On the other hand, the pulps of each species showed similar values for almost all components $(p>$ 0.05), except for fat content and energy value. The results obtained with the pulps and the seeds are comparable to those reported in different Opuntia species (Morales et al., 2012). The juice presented the lowest energetic value $(9.8 \mathrm{kcal} / 100 \mathrm{~g}$ fw for $O$. mycrodasis; $4.6 \mathrm{kcal} / 100 \mathrm{~g}$ fw for O. macrorhiza), while seeds gave the highest (201 $\mathrm{kcal} / 100 \mathrm{~g}$ fw for O. mycrodasis; $222 \mathrm{kcal} / 100 \mathrm{~g}$ fw for O. macrorhiza).

\subsection{Dietary fiber: soluble and insoluble fiber}

The contents in soluble dietary fiber (SDF), insoluble dietary fiber (IDF) and total dietary fiber (TDF) were evaluated in the cladodes, pulps and seeds (Table 3). The highest dietary fiber contents were detected in seeds $(\approx 40 \mathrm{~g} / 100 \mathrm{~g}$ fw for both species $)$. The detected amounts were considerably higher than those reported in the seeds of $O$. joconostle and O. matudae (Morales et al., 2012). The dietary fiber levels quantified in the cladodes and pulps were more than 10 -fold lower than those detected in the seeds, but higher than those reported for cladodes from Tunisian (Ayadi et al., 2009) and Mexican (Ramírez-Moreno et al., 2013) varieties of $O$. ficus indica, as well as, the pulps 
of O. joconostle and O. matudae (Morales et al., 2012). In all studied samples, the percentage of IDF was always higher than that of SDF, with the highest ratios detected in pulp fraction (75\% of IDF). The detected TDF amounts might represent an important contribution to achieve the Recommended Dietary Allowance (RDA), which recommends a daily consumption between 25 and $30 \mathrm{~g}$ of TDF (FAO/WHO, 2003), achievable with approximately $50 \mathrm{~g}$ of seeds. Furthermore, it is instructed that a third of total fiber should be soluble fiber (3:1 ratio), and the distribution of fiber in the cladode, pulp and seeds is in agreement with this recommendation. In this particular subject, $O$. mycrodasis and $O$. macrorhiza have similar potential as dietary fiber sources, since the only statistically significant differences were given by $\operatorname{SDF}(p=0.010)$ and $\operatorname{TDF}(p=$ $0.025)$ contents in the cladodes.

\subsection{Mineral composition (Macro and microelements)}

The microelements (Fe, $\mathrm{Cu}, \mathrm{Mn}$ and $\mathrm{Zn}$; expressed in $\mu \mathrm{g} / 100 \mathrm{~g}$ fw) and macroelements $(\mathrm{Ca}, \mathrm{Mg}, \mathrm{Na}$ and $\mathrm{K}$; expressed in $\mathrm{mg} / 100 \mathrm{~g}$ fw) profile are given in Table 4 . The cladodes and the pulp of the two Opuntia species presented similar profiles, despite the absence of copper in the pulp of $O$. macrorhiza. The seeds proved to be the most suitable source of microelements, especially regarding to the copper $(392 \mu \mathrm{g} / 100 \mathrm{~g} \mathrm{fw}$ in $O$. mycrodasis and $992 \mu \mathrm{g} / 100 \mathrm{~g}$ fw in $O$. macrorhiza $)$ and zinc $(143 \mu \mathrm{g} / 100 \mathrm{~g}$ fw in O. mycrodasis and $237 \mu \mathrm{g} / 100 \mathrm{~g} \mathrm{dw}$ in O. macrorhiza) levels. These microelements are crucial for important biochemical and physiological functions and essential for maintaining health throughout life (Li et al., 2014). Nevertheless, excess in zinc uptake can be harmful; indeed, excessive absorption of this microelement can suppress copper and iron absorption. Likewise, free copper causes toxicity in human body, as it generates reactive oxygen species such as superoxide, hydrogen peroxide, or the 
hydroxyl radical, that might damage proteins, lipids and DNA (Brewer, 2010). Our results for the cladodes of $O$. macrorhiza and $O$. mycrodasis are significantly different from those reported by Ayadi et al. (2009), despite being similar to those reported by El-Sayed et al., (2014). These discrepancies could be most likely due to genotypic factors and environmental cultivar conditions.

In terms of macroelements composition, calcium, magnesium, sodium and potassium were detected, with potassium as the major element in all studied samples, except in the seeds of $O$. macrorhiza, in which calcium reached the highest values (Table 4). The prevalence of potassium among the macroelements profile is in agreement with the results obtained in Opuntia genus (Abdel-Hameed et al., 2014; Chávez et al., 1995). Potassium is a very important component for human health; in fact, highpotassium diet lowers blood pressure and reduces cardiovascular disease morbidity and mortality (Whelton et al., 1997). In addition, potassium intake lowers urinary calcium excretion and decreases the risk of osteoporosis (He and MacGregor, 2008). Sodium was quantified in relative low amounts, which might be considered as a favorable result in view of the need to consume low quantities of this mineral. Magnesium, quantified in highest amounts in the seeds of $(7.3 \mathrm{mg} / 100 \mathrm{~g} \mathrm{fw})$ and the cladodes $(5.8 \mathrm{mg} / 100 \mathrm{~g} \mathrm{fw})$ of $O$. mycrodasis, has a direct role

in promoting endothelial dysfunction by generating a pro-inflammatory, pro-thrombotic and pro-atherogenic environment, that could play a role in the pathogenesis of cardiovascular disease (Maier et al., 2004).

According to Regulation (EU) No 1169/2011 and Food and Nutrition Board (Trumbo et al., 2002), the consumption of $100 \mathrm{~g}$ (fw) of these Opuntia spp. are noteworthy for its interesting contribution to $\mathrm{Cu}$, with values up to 39.2 and $99.2 \%$ RDA for adults, in $O$. mycrodasis and O. macrorhiza, respectively. 


\subsection{Principal component analysis (PCA)}

In the former sections, the differences among the studied parameters were compared considering the contribution of each Opuntia species. Another interesting study would be defining the best botanical part (cladode, pulp or seed) that would allow obtaining a specific constituent in a desired amount. Accordingly, in the present section, the results were evaluated considering data for all studied parts and parameters simultaneously, by applying a principal components analysis (PCA). The morphological parameters were not included in this analysis, since their high differences would have caused a biased effect.

The plot of object scores (Figure 2), for different Opuntia parts, indicates that the first two dimensions (first: Cronbach's $\alpha, 0.981$; eigenvalue, 11.189; second: Cronbach's $\alpha$, 0.491; eigenvalue, 1.837) account for most of the variance of all quantified variables (79.9\% and $13.1 \%$, respectively). Groups corresponding to each part (cladode, pulp and seed) were not completely individualized, since pulps and cladodes were placed together (except for the cladodes of $O$. mycrodasis). Nevertheless, seeds were clearly separated from the remaining parts, including among both species. By considering all the results together, it becomes obvious that seeds are the best source of micro and macroelements, nutritional compounds and fibers. However, the high energy levels for these components might be considered a limitation. The high difference in moisture contents among seeds and the remaining parts contributed greatly for the observed separation, but results seem to indicate that pulps and cladodes present similar profiles in the studied parameters.

\section{Conclusions}


Despite the morphological distinctiveness, the studied Opuntia species proved to have some similarity regarding their nutritional, dietary fiber and mineral elements profiles. However, the greater differences were found among the different studied parts: cladodes, pulp and seeds. In fact, each of these parts proved its potential to act as a new source of specific constituents, allowing the recommendation of defined dietary doses in accordance with the RDA to supply different nutritional requirements.

\section{Acknowledgments}

The authors are grateful to Fundação para a Ciência e a Tecnologia (FCT, Portugal) for financial support to CIMO (strategic project PEst-OE/AGR/UI0690/2011) and ALIMNOVA research group (UCM-GR35/10A). J.C.M. Barreira thanks FCT, POPH-

QREN and FSE for his grant (SFRH/BPD/72802/2010). L. Barros thanks “Compromisso para a Ciência 2008” for her contract.

\section{References Formatar de acordo com a revista}

Abdel-Hameed, E.-S.S., Nagaty, M.A., Salman, M.S., Bazaid, S.A. (2014). Phytochemicals, nutritionals and antioxidant properties of two prickly pear cactus cultivars (Opuntia ficus indica Mill.) growing in Taif, KSA. Food Chemistry, 160, $31-38$.

Ayadi M.A., Abdelmaksoud W., Ennouri M., Attia H. (2009). Cladodes from Opuntia ficus indica as a source of dietary fiber: Effect on dough characteristics and cake making. Industrial Crops and Products, 30, 40-47.

Bergaoui A, Boughalleb N, Jannet HB, Harzallah-Shiric F, El Mahjoub M and Mighri Z. (2007). Chemical Composition and Antifungal Activity of Volatiles from three 
species Growing in Tunisia. Pakistan Journal of Biological Sciences. 10 (15), $2485-2489$.

Brewer G.J. (2010). Copper toxicity in the general population. Clin. Neurophysiol., 121, $459-460$.

Chávez, M.M., Chávez, A., Valles, V., Roldán J.A. (1995). The nopal: a plant of manifold qualities. World Review of Nutrition and Dietetics, 77, 109-134.

FAO/WHO. (2003). Technical report series, No. 916, Diet, nutrition and the prevention of chronic diseases, WHO, Geneva.

Felker P.,Rodriguez S., Casoliba R.M., Filippini R., Medina D., Zapata R. (2005). Comparison of Opuntia ficus-indica varieties of Mexican and Argentine origin for fruit yield and quality in Argentina .Journal of Arid Environments, 60 (3), 405422.

Fernández-Ruiz, V., Olives Barba, A.I., Sanchez-Mata, M.C., Camara, M., Torija, M.E. (2011). Mineral and Trace Elements Content in 30 Accessions of Tomato Fruits (Solanum lycopersicum L.,) and Wild Relatives (Solanum pimpinellifolium L., Solanum cheesmaniae L. Riley, and Solanum habrochaites S. Knapp \& D.M. Spooner). Biological Trace Element Research, 141, 329-339.

He, F., MacGregor, G. (2008). Beneficial effects of potassium on human health. $J$. Plant. Biol., 133, 725-735.

IFST, The Institute of Food Science \& Technology, through its Public Affairs and Technical \& Legislative Committees, has authorised the following Information Statement, dated April 2007, updating that of February 2007.

Jae Hwan K., Jung Lee H., Hyun-Sun L., Eun-Jeong L., Jee-Young I., Hyung Joo S.(2012). Physical and sensory characteristics of fibre-enriched sponge cakes made with Opuntia humifusa. LWT - Food Science and Technology, 47, 478-484. 
Latimer, G.W. (2012). Official methods of analysis of AOAC international (18th ed.). Gaithersburg: EEUU.

Lee J., Kim H., Kim J., Jang Y. (2002). Antioxidant property of an ethanol extract of the stem of Opuntia ficus-indica var. Saboten. Journal of Agriculture and Food Chemistry, 50 (22), 6490-6496.

Li Z., Ma Z., Jan van der Kuijp T., Yuan Z., Huang L. (2014). A review of soil heavy metal pollution from mines in China: pollution and health risk assessment. Sci. Total Environ., 468-469, 843-853.

Maier, J.A., Malpuech-Brugère C., Zimowska, W., Rayssiguier, Y., Mazur, A. (2004). Low magnesium promotes endothelial cell dysfunction: implications for atherosclerosis, inflammation and thrombosis. Biochimica et Biophysica Acta, $1689,13-21$.

McDowell, L.R., 2003. Minerals in Animal and Human Nutrition, 2nd ed. Amsterdam, The Netherlands, Elsevier.

Morales P., Ramírez-Moreno E., Sanchez-Mata, M. C., Carvalho.A. A.M, Ferreira I.C.F.R. (2012). Nutritional and antioxidant properties of pulp and seeds of two xoconostle cultivars (Opuntia joconostle F.A.C. Weber ex Diguet and Opuntia matudae Scheinvar) of high consumption in Mexico. Food Research International, 46 (1), $279-285$.

Nabrzyski M. Szefer P., Nriagu J.O. (2007). Functional role of some minerals in foods. Mineral Components in Foods, CRC Press, Taylor Francis Group, London New York, 363-388.

Piga A. (2004). Cactus pear: a fruit of nutraceutical and functional importance. Journal of Professional Association Cactus Development, 6, 9-22. 
Prieto-García F., Filardo-Kerstup S., Pérez-Cruz E., Beltrán-Hernández R., RománGutiérrez A., Méndez-Marzo M. (2006). Caracterización física y química de semillas de Opuntias (Opuntia spp.) cultivadas en el estado de Hidalgo, Mexico. Bioagrociencia., 18,163-169.

Ramírez-Moreno, E., Córdoba-Díaz, D., Sánchez-Mata, M.C., Díez-Marqués, C., Goñi, I. (2013). Effect of boiling on nutritional, antioxidant and physicochemical characteristics in cladodes (Opuntia ficus indica). LWT - Food Science and Technology, 51, 296-302.

Regulation (EC) No 1169/2011 of the European Parliament and of the Council, of 25 October 2011, on the provision of food information to consumers. Official Journal of the European Union. 22.11.2011. L 304/18- 63.

Ruiz-Rodríguez B, Morales P, Fernández-Ruiz V, Sánchez-Mata MC, Cámara M, DíezMarqués C, Santayana MP, Molina M, Tardío J (2011).Valorization of wild strawberry tree fruits (Arbutus unedo L.) through nutritional assessment and natural production data. Food Research International 44:1244-1253

Sawaya W.N., Khan P. (1982). Chemical characterization of prickly pear seed oil, Opuntia ficus-indica. Journal of Food Science, 47, 2060-2061.

Soetan K. O., Olaiya C. O. and Oyewole O. E.(2010). The importance of mineral elements for humans, domestic animals and plants: A review. African Journal of Food, 4(5), 200-222.

Ternent C.A., Bastawrous A.L., Morin N.A., Ellis C.N., Hyman N.H., Buie W.D. (2007). Practice parameters for the evaluation and management of constipation. Diseases of the Colon and Rectum, 50, 2013-2022. 
Touil, A., Chemkhi, S., Zagrouba, F. (2010). Modelling of the drying kinetics of Opuntia ficus indica fruits and cladodes. International Journal of Food Engineering, 6, 1-15.

Trumbo, P., Schlicker, S., Yates, A.A., Poos, M. (2002). Dietary reference intakes for energy, carbohydrate, fiber, fat, fatty acids, cholesterol, protein and amino acids. Journal of American Dietetics Association 102, 1621-1630.

Valdez-Cepeda R.D., Blanco-Macías F., Magallanes-Quintanar R., Vázquez-Alvarado R., Méndez-Gallegos S.J. (2013). Fruit weight and number of fruits per cladode depend on fruiting cladode fresh and dry weight in Opuntia ficus-indica (L.) Miller variety‘Rojo pelón’. Scientia Horticulturae, 161, 165-169.

Whelton P., He J., Cutler J., Brancati F., Appel L., Follmann D., Kleg M. (1997). Effects of oral potassium on blood pressure. Meta-analysis of randomized controlled clinical trials. J. Am. Med. Assoc., 277, 1624-1632. 
Table 1. Morphological characteristics of fresh cladodes, whole fruits and seeds of Opuntia microdasys (Lehm.) Pfeiff and Opuntia macrorhiza (Engelm.)

\begin{tabular}{llccc}
\hline \multicolumn{1}{c}{ Sample } & \multicolumn{1}{c}{ Species } & Length $(\mathrm{cm})$ & Width $(\mathrm{cm})$ & Weight $(\mathrm{g})$ \\
\hline \multirow{2}{*}{ Cladode } & O. mycrodasis & $12 \pm 2$ & $9 \pm 2$ & $63 \pm 1$ \\
& O. macrorhiza & $23 \pm 2$ & $14 \pm 2$ & $163 \pm 2$ \\
\cline { 2 - 5 } & $t$-student $p$-value & 0.001 & 0.027 & $<0.001$ \\
\hline \multirow{2}{*}{ Fruit } & O. mycrodasis & $3.3 \pm 0.2$ & $2.7 \pm 0.3$ & $7 \pm 1$ \\
& $O$. macrorhiza & $5.0 \pm 0.1$ & $3.3 \pm 0.1$ & $35 \pm 1$ \\
\cline { 2 - 5 } & $t$-student $p$-value & $<0.001$ & 0.027 & $<0.001$ \\
\hline \multirow{2}{*}{ Seed } & $O$. mycrodasis & $0.20 \pm 0.05$ & $0.12 \pm 0.02$ & $0.017 \pm 0.005$ \\
& $O$. macrorhiza & $0.40 \pm 0.05$ & $0.32 \pm 0.03$ & $0.06 \pm 0.01$ \\
\cline { 2 - 5 } & $t$-student $p$-value & 0.008 & 0.001 & 0.003 \\
\hline
\end{tabular}


Table 2. Nutritional composition (g/100g fw) of different parts of Opuntia microdasys (Lehm.) Pfeiff and Opuntia macrorhiza (Engelm.)

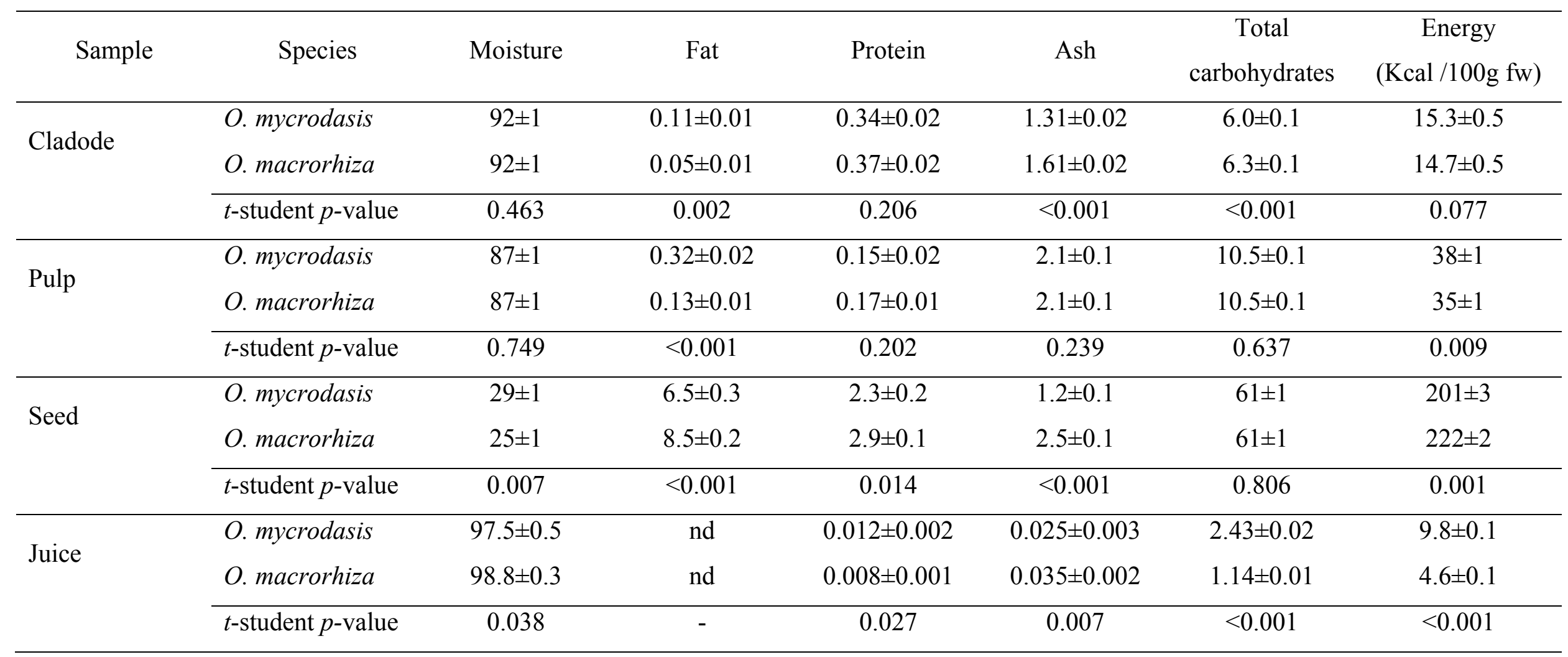

nd: not detected; fw: fresh weight. 
Table 3. Soluble, insoluble and total dietary fiber (g/100 g fw) of Opuntia microdasys (Lehm.) Pfeiff and Opuntia macrorhiza (Engelm.)

\begin{tabular}{llccc}
\hline \multicolumn{1}{c}{ Sample } & \multicolumn{1}{c}{ Species } & $\begin{array}{c}\text { Insoluble dietary } \\
\text { fiber (IDF) }\end{array}$ & $\begin{array}{c}\text { Soluble dietary } \\
\text { fiber (SDF) }\end{array}$ & $\begin{array}{c}\text { Total dietary } \\
\text { fiber (TDF) }\end{array}$ \\
\hline \multirow{2}{*}{ Cladode } & O. mycrodasis & $3.3 \pm 0.1$ & $2.1 \pm 0.2$ & $5.4 \pm 0.2$ \\
& O. macrorhiza & $3.4 \pm 0.2$ & $2.7 \pm 0.2$ & $6.2 \pm 0.1$ \\
\cline { 2 - 5 } & $t$-student $p$-value & 0.250 & 0.010 & 0.025 \\
\hline \multirow{2}{*}{ Pulp } & O. mycrodasis & $3.0 \pm 0.3$ & $0.98 \pm 0.05$ & $4.0 \pm 0.4$ \\
& $O$. macrorhiza & $3.3 \pm 0.2$ & $0.98 \pm 0.05$ & $4.3 \pm 0.3$ \\
\cline { 2 - 5 } Seeds & $t$-student $p$-value & 0.153 & 0.995 & 0.242 \\
\cline { 2 - 5 } & $O$. mycrodasis & $40 \pm 1$ & $15 \pm 1$ & $56 \pm 1$ \\
& $O$. macrorhiza & $39 \pm 2$ & $16 \pm 1$ & $55 \pm 1$ \\
\cline { 2 - 5 } & $t$-student $p$-value & 0.555 & 0.912 & 0.510 \\
\hline
\end{tabular}

fw: fresh weight 
Table 4. Microelements ( $\mathrm{Fe}, \mathrm{Cu}, \mathrm{Mn}$ and $\mathrm{Zn}$, in $\mu \mathrm{g} / 100 \mathrm{~g}$ fw) and macroelements (Ca, $\mathrm{Mg}, \mathrm{Na}$ and $\mathrm{K}$, in $\mathrm{mg} / 100 \mathrm{~g}$ fw) in different parts of Opuntia microdasys (Lehm.) Pfeiff and Opuntia macrorhiza (Engelm.)

\begin{tabular}{|c|c|c|c|c|c|c|c|c|c|}
\hline Sample & Species & $\mathrm{Fe}$ & $\mathrm{Cu}$ & $\mathrm{Mn}$ & $\mathrm{Zn}$ & $\mathrm{Ca}$ & $\mathrm{Mg}$ & $\mathrm{Na}$ & $\mathrm{K}$ \\
\hline \multirow{3}{*}{ Cladode } & O. mycrodasis & $6 \pm 1$ & $0.08 \pm 0.01$ & $3.2 \pm 0.5$ & $0.7 \pm 0.2$ & $2.4 \pm 0.2$ & $5.8 \pm 0.5$ & $0.006 \pm 0.002$ & $18 \pm 2$ \\
\hline & O. macrorhiza & $6 \pm 1$ & $0.33 \pm 0.05$ & $4.2 \pm 0.5$ & $0.8 \pm 0.1$ & $3.0 \pm 0.1$ & $1.6 \pm 0.1$ & $1.14 \pm 0.05$ & $4.3 \pm 0.1$ \\
\hline & $t$-student $p$-value & 0.770 & 0.006 & 0.142 & 0.651 & 0.019 & 0.008 & 0.001 & $<0.001$ \\
\hline \multirow{3}{*}{ Pulp } & O. mycrodasis & $4 \pm 1$ & $0.13 \pm 0.01$ & $4 \pm 1$ & $4 \pm 1$ & $5.7 \pm 0.1$ & $0.61 \pm 0.05$ & $0.19 \pm 0.02$ & $94 \pm 2$ \\
\hline & O. macrorhiza & $5 \pm 1$ & nd & $5 \pm 1$ & $0.38 \pm 0.05$ & $5.8 \pm 0.3$ & $0.63 \pm 0.03$ & $1.1 \pm 0.1$ & $31 \pm 3$ \\
\hline & $t$-student $p$-value & 0.110 & - & 0.130 & $<0.001$ & 0.545 & 0.705 & $<0.001$ & $<0.001$ \\
\hline \multirow{3}{*}{ Seed } & O. mycrodasis & $94 \pm 7$ & $392 \pm 21$ & $64 \pm 8$ & $143 \pm 16$ & $76 \pm 6$ & $7.3 \pm 0.5$ & $13 \pm 1$ & $176 \pm 11$ \\
\hline & O. macrorhiza & $37 \pm 5$ & $992 \pm 65$ & $158 \pm 11$ & $237 \pm 26$ & $89 \pm 6$ & $5.1 \pm 0.3$ & $8 \pm 1$ & $63 \pm 2$ \\
\hline & $t$-student $p$-value & $<0.001$ & $<0.001$ & $<0.001$ & 0.006 & 0.068 & 0.009 & 0.005 & $<0.001$ \\
\hline \multirow{3}{*}{ Juice } & O. mycrodasis & $11 \pm 2$ & $2.5 \pm 0.5$ & nd & nd & $0.32 \pm 0.05$ & $0.43 \pm 0.02$ & $0.8 \pm 0.1$ & $3.4 \pm 0.4$ \\
\hline & O. macrorhiza & $1.0 \pm 0.2$ & nd & $1.0 \pm 0.1$ & $2.8 \pm 0.2$ & $0.21 \pm 0.04$ & $0.28 \pm 0.05$ & $0.10 \pm 0.01$ & $2.0 \pm 0.1$ \\
\hline & $t$-student $p$-value & 0.001 & - & - & - & 0.071 & 0.008 & 0.001 & 0.003 \\
\hline
\end{tabular}

nd: not detected; fw: fresh weight 


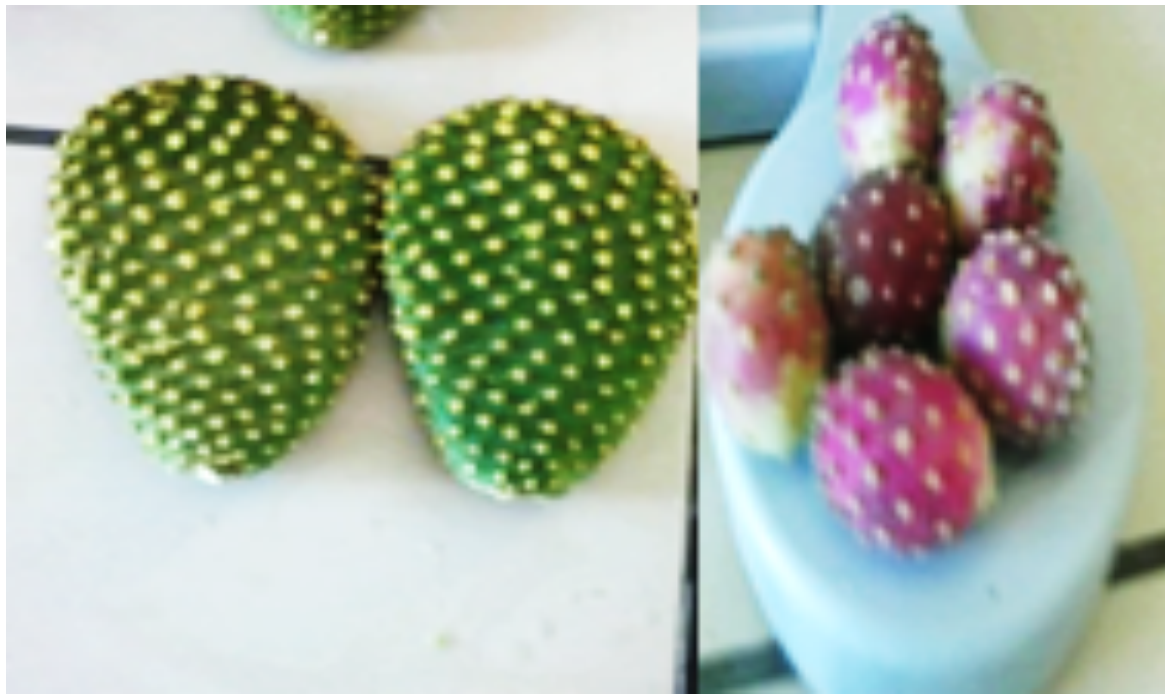

(A)

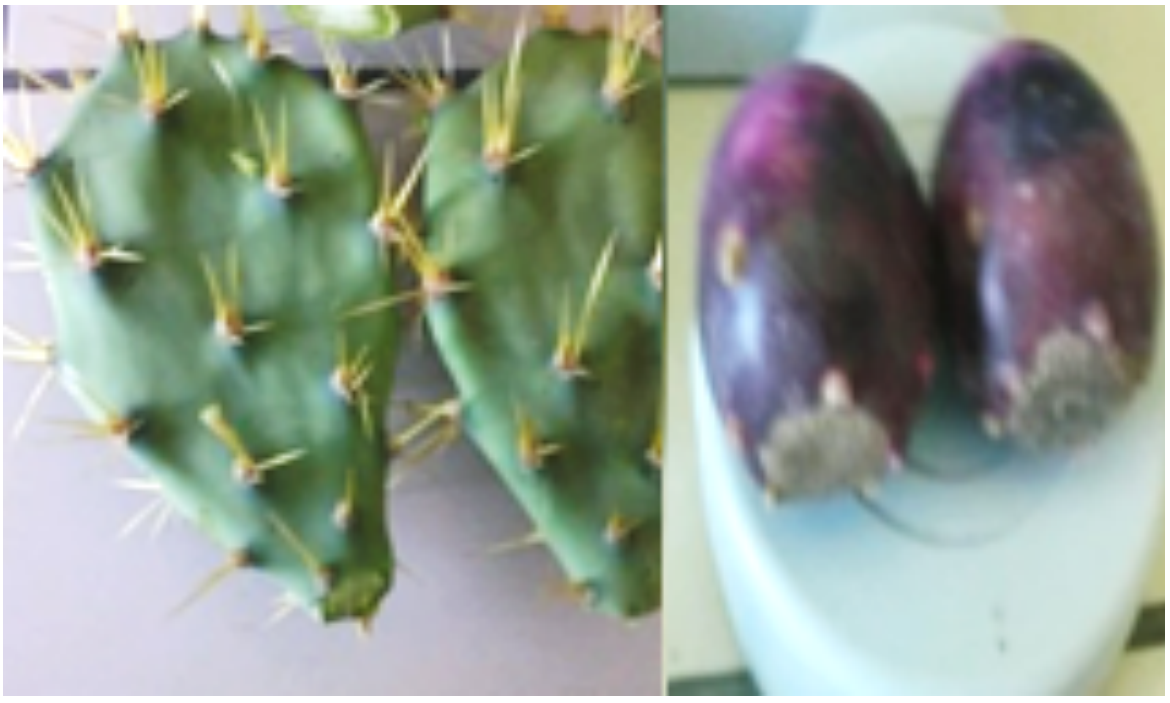

(B)

Figure 1. Cladodes (green parts) and whole fruits (purple parts) of Opuntia myc and Opuntia macrorhiza (B). 


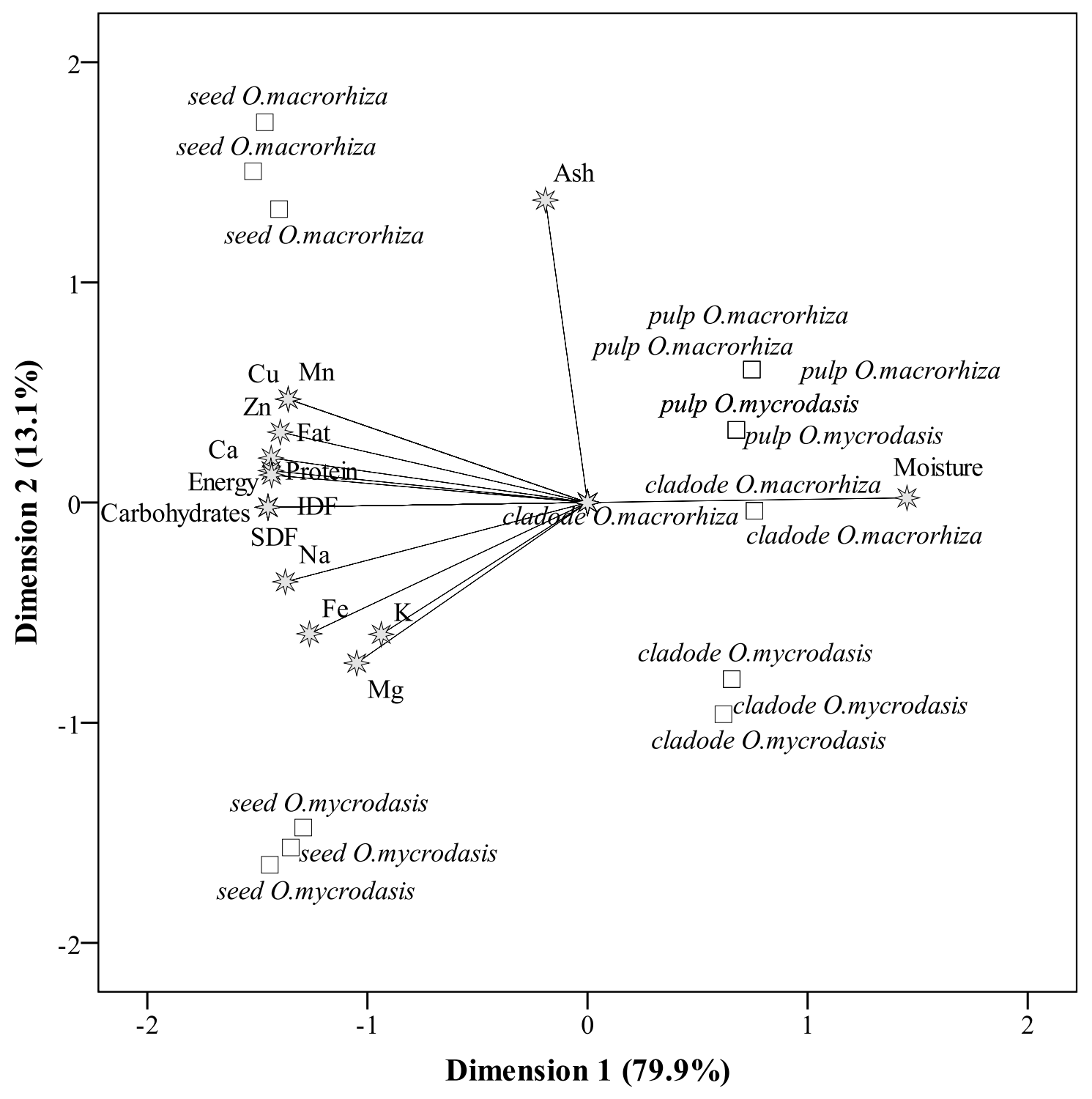

Figure 2. Biplot of object (different studied parts) scores and component loadings (evaluated parameters). 